\title{
P01-114
}

\section{A RANDOMIZED AND DOUBLE- BLIND CLINICAL TRIAL OF VENLAFAXINE HYDROCHLORIDE SUSTAINED RELEASE CAPSULES FOR TREATING JUVENILE DEPRESSION}

C. Hongfen ${ }^{1}$, J. Weidong ${ }^{1}$, Z. Guoquan ${ }^{1}$, Y. Chuang ${ }^{2}$, G. Tianyou ${ }^{3}$

${ }^{1}$ Psychiatry, Shanghai Changning Mental Health Center/Bio-X Center Hospital of Shanghai Jiaotong University, Shanghai, ${ }^{2}$ Psychiatry, Wenzhou Medical Collage, Wenzhou, ${ }^{3}$ Psychology, Shenzhen University, Shenzhen, China

Object: To evaluate the efficacy and safety of venlafaxine hydrochloride $(\mathrm{HCL})$ sustained release capsules in treating juvenile with depressive disorder.

Methods: A randomized, double blind dummy clinical trial enrolled 60 adolescent patients with depression, who were randomizedly designed to administer venlafaxine HCL sustained release capsules $150 \mathrm{mg}$ or fluoxetine $20 \mathrm{mg}$ daily for 8 weeks. The efficacies of both treatment groups was evaluated based on the Hamilton Depression Scale and Clinical General impression Scale pre and posttreatment.

Results: The scores of Hamilton Depression Scale at the end of therapy were significantly reduced compared with the baseline in both gtnups $(\mathrm{P}<0.01)$. The effective rate of venlafaxine $\mathrm{HCL}$ sustained release capsules versus fluoxetine treatmlent was $70.0 \%$ and $65.5 \%$, respectively, the $P$ value showed no statistical difference $(P>0$. OS). The common adverse reactions included dry mouth, insomnia, dizziness, and loss of appetite.

Conclusion: Venlafaxine $\mathrm{HCl}$ sustained release capsules is an effective agent for juvenile with major depression. 